\title{
Comparison of HCV viral load and its genotype distributions in HCV mono- and HIV/HCV co-infected illicit drug users
}

\author{
Marzieh Jamalidoust ${ }^{1 *}$, Mandana Namayandeh ${ }^{1}$, Mohsen Moghadami ${ }^{2}$ and Mazyar Ziyaeyan ${ }^{1}$
}

\begin{abstract}
Background: Because of shared modes of transmission, patients with hepatitis C virus (HCV) infection are often coinfected with other types of hepatitis viruses and/or HIV. We studied HCV viral load and its genotype patterns among HCV mono- and HCV/HIV co-infected Illicit Drug Users in Fars province-Iran.

Methods: Totally, 580 HCV seropositive IDUs referred to Prof. Alborzi Clinical Microbiology Research Center, Shiraz, Iran, without receiving any anti-HCV treatment, were enrolled. After their HCV infections were reconfirmed by one step rapid diagnostic test, HCV RNA level and HCV genotypes were determined by Taq-man real-time PCR assays. Their HIV serostatus was determined and seropositive patients were excluded from the group. In addition, 104 HIV/HCV co-infected IDUs referred from Shiraz Behavioral Diseases Consultation Center (SBDC) were assessed for HCV RNA level and HCV genotype patterns, as well.
\end{abstract}

Results: The overall estimated HIV prevalence was 6.7\% (39/580) among HCV seropositive IDUs. Genotype 1, the most prevalent genotype in both groups, was detected in $69 \%$ and $49 \%$ of co- and mono-infected IDUs,

respectively. Median HCV viral load was significantly higher in HIV/HCV co-infected patients, compared with that among HCV mono-infected counterparts.

Conclusions: Given the higher baseline HCV viral load and GT1 attributed to poorer treatments response, HCV treatment must be more considered among HCV/HIV co-infected IDUs, compared to those mono-infected with HCV.

Keywords: Hepatitis C virus, HIV, HCV genotypes, Illicit drug users, Quantitative PCR assay

\section{Background}

Hepatitis C Virus $(\mathrm{HCV})$ is the most important cause of liver diseases that may co-occur with Human Immunodeficiency Virus (HIV) [1]. Globally, among 170 million of HCV infected patients, 4-5 million are co-infected with HIV, worldwide [2, 3]. Nowadays, predominant group of $\mathrm{HCV}$ infected population are Illicit Drug Users (IDUs) [4]. Syringe sharing and tattooing are the most risk factors in the acquisition of both HCV and HIV infections in IDU sufferers [5].

WHO reports nearly 13 million IDUs exist in the world and $67 \%, 13 \%$ and $8.4 \%$ of them are living with

\footnotetext{
*Correspondence: mjamalidoust@gmail.com

'Department of Virology, Professor Alborzi Clinical Microbiology Research Center, Nemazi Hospital, Shiraz University of Medical Sciences, P. O. Box: 31, Shiraz 71937-11351, Iran

Full list of author information is available at the end of the article
}

$\mathrm{HCV}$, $\mathrm{HIV}$ and $\mathrm{HCV} / \mathrm{HIV}$ co-infection, respectively http://www.who.int/hiv/mediacentre/news/global-aidsupdate-2016-news/en/. Some studies indicated that 1.2 million permanent addicts and approximately 2.5 million recreational IDUs exist in Iran with $\mathrm{HCV}$ and $\mathrm{HCV} / \mathrm{HIV}$ co-infection frequencies of 45 and $11 \%$, respectively [6].

Although HCV and HIV can be transmitted by the same route; the rates of their transmission vary in different high risk groups [4]. In IDUs, with small amount of infected blood percutaneous exposure, $\mathrm{HCV}$ is approximately 10 times more easily transmitted than HIV and about $30 \%$ of HCV infected IDUs have HIV infection, also. Meanwhile, in hemophiliacs, another high risk group with large volume blood transfusion, approximately all HIV infected patients are also co-infected with HCV infection [7]. 
HCV has appeared as a common cause and a major concern in the treatment of HIV infection after introduction of HAART (High Activity Anti-Retroviral Therapy) therapy [8]. HCV-associated liver dysfunction has become the main cause of morbidity and mortality in IDUs co-infected with HIV [9]. Many studies revealed that $\mathrm{HCV}$ viral load, $\mathrm{HCV}$ viremia persistency, response to $\mathrm{HCV}$ standard therapy and median hepatic fibrosis rate progression in $\mathrm{HIV} / \mathrm{HCV}$ co-infected patients are significant, compared with those in $\mathrm{HCV}$ mono-infected ones [9-11].

Although HCV RNA detection and quantification is the standard method for diagnosis of active HCV infection [3], HCV genotyping is a critical test for determination of treatment duration regime.

In the current study, besides determination of seroprevalence of HIV infection among HCV infected IDUs, $\mathrm{HCV}$ viral loads were determined in $\mathrm{HCV}$ monoinfected IDUs as well as $\mathrm{HIV} / \mathrm{HCV}$ co-infected patients. Also, we evaluated HCV GTs in both groups of patients.

\section{Methods}

\section{Patient's selection}

To be eligible for this study, patients had to be herbal and/or chemical IDUs, be HCV seropositive, age > 15 years with no previous $\mathrm{HCV}$ treatment. All included patients have aminotransferase level within the reference range. This study was performed between April 2011 and September 2015, consisting of two main groups a) 580 HCV seropositive IDUs majority from Shiraz university of medical science- Hepatitis clinic and b) 104 HIV/HCV coinfected IDUs referred from Shiraz Behavioral Diseases Consultation Center (SBDC) in Fars Province, southern Iran. All patients referred to Prof. Alborzi Clinical Microbiology Research Center (PACMRC) for more examination. They were interviewed face-to-face and their demographic data and risks were recorded. The liver enzyme level data were checked by reviewing of patients medical records.

Hepatitis clinic, SBDC and PACMRC are institutions affiliated with Shiraz University of medical sciences.

\section{HCV laboratory diagnostic tests}

The presence of specific HCV antibodies in sera samples from infected IDUs referred to PACMRC were reconfirmed with GB anti-HCV V4.0 ELISA kit (Hsinchu science park-Taiwan), according to manufacturer's guideline.

Five hundred eighty anti-HCV positive specimens as well as 104 anti- $\mathrm{HIV} / \mathrm{HCV}$ positive samples were further tested with commercially available $\mathrm{HCV}$ kits (Genome Diagnostics Pvt. Ltd., Hague, Netherland). In the first step, viral RNA genomes were extracted from $200 \mu \mathrm{L}$ of $\mathrm{HCV}$ mono infected and HCV/HIV coinfected specimens using Invitek kit (Berlin- Germany), according to the guideline described. In the next step, $5 \mu \mathrm{L}$ of each extracted sample subjected to quantitative HCV RT- PCR test with commercially available HCV quantification kits (Genome Diagnostics Pvt. Ltd., Hague, Netherland), according to the manufacturer's instructions using 7500 Real-Time PCR system tool (Applied Biosystems, USA), and in the end, HCV genotyping was performed to determine HCV GTs 1-4 among patients who had HCV RNA positive specimens by real-time PCR assay using commercially available kits (Genome Diagnostics Pvt. Ltd., Hague, Netherland) and 7500 Real-Time PCR system tool.

\section{HIV laboratory diagnostic tests}

All HCV seropositive IDUs (with or without HIV infection) referred to PACMRC were screened and/or reconfirmed for HIV by ELISA test (Dia.pro-Milan-Italy). New identified HIV cases in PACMRC were introduced to SBDC as the main HIV consulting center for further hygienic proceeding toward HIV infection.

\section{Statistical analysis}

The data were analyzed using SPSS for Windows systems (Version 16.0, 2007, SPSS Inc., Chicago, IL, United States). We compared Median viral loads in the two groups by Man-Whitney test. We used $\chi^{2}$ test to evaluate HCV GTs patterns.

\section{Results}

As the initial result of this study, it was found that HIV seropositivity rate among $\mathrm{HCV}$ infected IDUs was $6.7 \%$ (39/580). As mention before, the new identified HIV cases referred to SBDC for further consultation and treatment.

HCV plasma RNA was detected in $79.11 \%(428 / 541)$ and $75 \%(78 / 104)$ of $\mathrm{HCV}$ mono- and HCV/HIV coinfected patients, respectively (Table 1 ), the difference was not statistically significant $(p \geq 0.05)$.

To investigate our hypothesis that HCV load in HIV/ $\mathrm{HCV}$ co-infected IDUs is higher than patients who infected only with HCV, the median HCV RNA load was compared in two subjected groups.

As shown in Fig. 1 after excluded undetectable HCV genome samples, it was revealed that the median $\mathrm{HCV}$ viral load is significantly higher (approximately 10 times) in $\mathrm{HCV} / \mathrm{HIV}$ co-infected $(n=78)$ IDUs compared with that in HCV mono-infected patients $(n=428)(p<0.05)$.

It's notable that none of the IDUs had received any $\mathrm{HCV}$ treatment before quantification of $\mathrm{HCV}$ load and assessment of their HCV GTs.

We also inquire age and sex as potential factors that may be effect on $\mathrm{HCV}$ viral load in two subjected groups. Men was predominant in HCV infected IDUs as well as co-infected ones meanwhile $98 \%$ and $89 \%$ of 
Table 1 Demographic and HCV virological status of Iranian HCV infected IDUs with or without HIV infection

\begin{tabular}{lll}
\hline Characteristics & HCV seropositive IDUs & HIV/HCV seropositive IDUs \\
\hline Total number (male/female) & $580(570 / 10)$ & $104(93 / 11)$ \\
Mean age & $37.8(\mathrm{SD} \pm 7.15)$ & $38.3(\mathrm{SD} \pm 10.66)$ \\
HIV seropositivity rate & $6.7 \%$ & $100 \%$ \\
HCV genome detection rate & $79 \%(428 / 541)^{\mathrm{a}}$ & $75 \%(78 / 104)$ \\
Median viral load among detectable HCV genome & 338,880 & $3549,908^{\mathrm{c}}$ \\
\hline
\end{tabular}

${ }^{\mathrm{a}} \mathrm{HCV}$ RNA detection was performed after excluded HCV/HIV co-infected patients

${ }^{b}$ Median viral load evaluated among HCV RNA detected sera samples

'The viral load unit in our study was copy/ml of serum sample

mono- and co-infected IDUs were male, respectively. The mean age of two groups did not differ significantly.

As shown in Fig. 2, 35-45 age group was the most prevalent age range in $\mathrm{HIV} / \mathrm{HCV}$ affected patients with frequency greater than $50 \%$ whereas in $\mathrm{HCV}$ monoinfected patients aged 25-35 the infection accounted for about $40 \%$.

We also assessed HCV GTs in the two groups. HCV genotyping was performed on 428/541 HCV mono- and 78/104 HCV/HIV co-infected IDUs, who had detectable HCV RNA. Of them, 348/428 (81.30\%) HCV monoinfected and 68/78 (87.17\%) HCV/HIV co-infected IDUs were genotyped successfully using $\mathrm{HCV}$ genotype realtime kit from Applied Biosystem (Table 2). GT1 was predominant in both of them, but in HCV/HIV co-infected
IDUs, GT1 was significantly higher than that in monoinfected counterparts $(p \geq 0.5)$. GT3 was the second most common genotype in both groups but its prevalence was more than approximately 1.5 -folds in mono-infected IDUs. There was not seen any mix genotype and GT4 $\mathrm{HCV}$ infection in $\mathrm{HIV} / \mathrm{HCV}$ co-infected patients. Meanwhile $9 \mathrm{HCV}$ mono-infected cases had GT1 of which 7 and 2 were with GT3 and GT2, respectively. The frequency and distribution of HCV GTs among HCV mono and/or co-infected IDUs has been shown in Table 2.

According to Table 3, 81/104 (78\%) HCV/HIV co- and 295/541 (54\%) HCV mono- infected patients had prison life experience (from few months to several months). Tattooing is another risk factor that was seen in 28 and $30 \%$ of $\mathrm{HCV} / \mathrm{HIV}$ co- and HCV mono- infected IDUs,

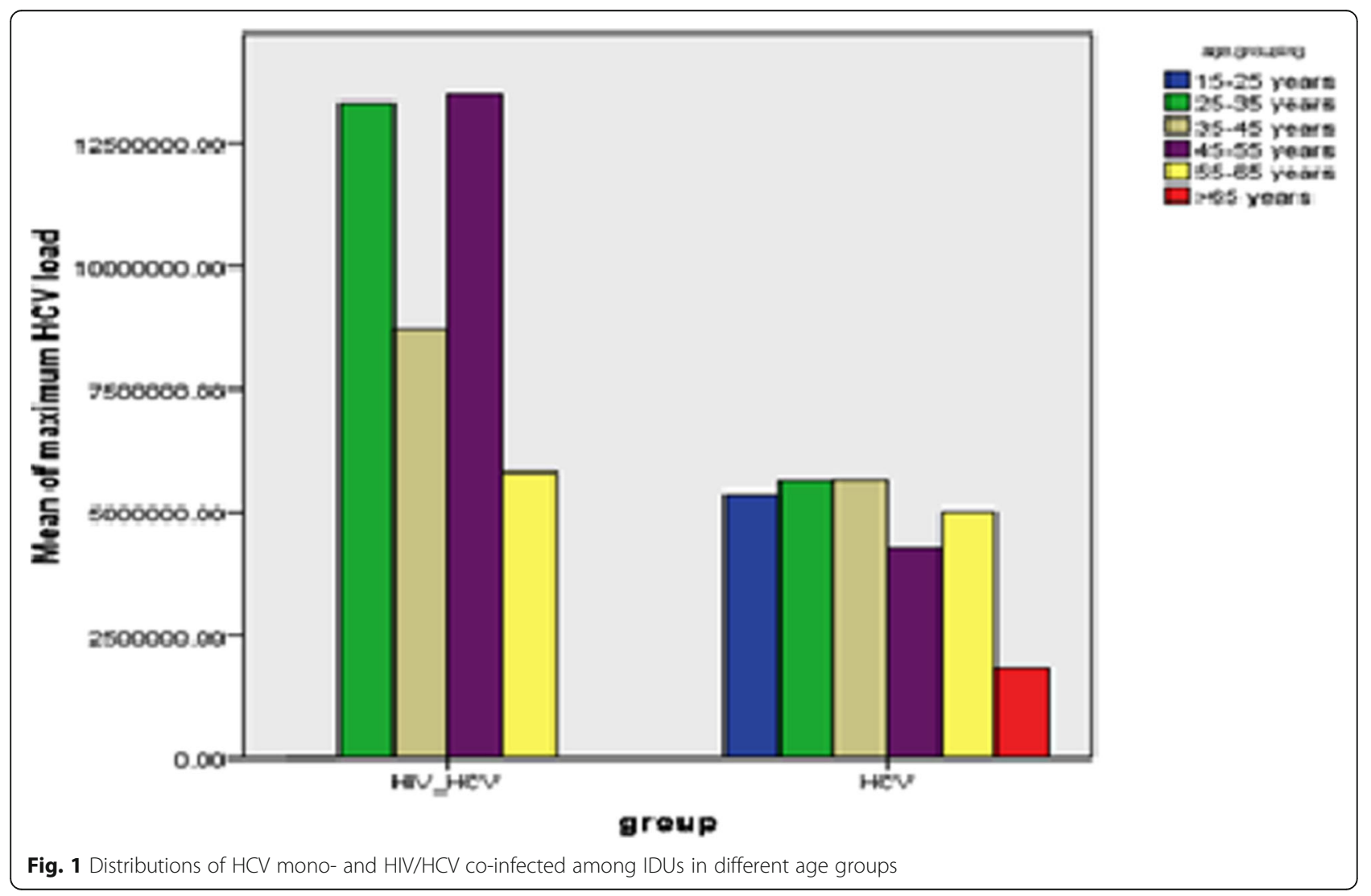




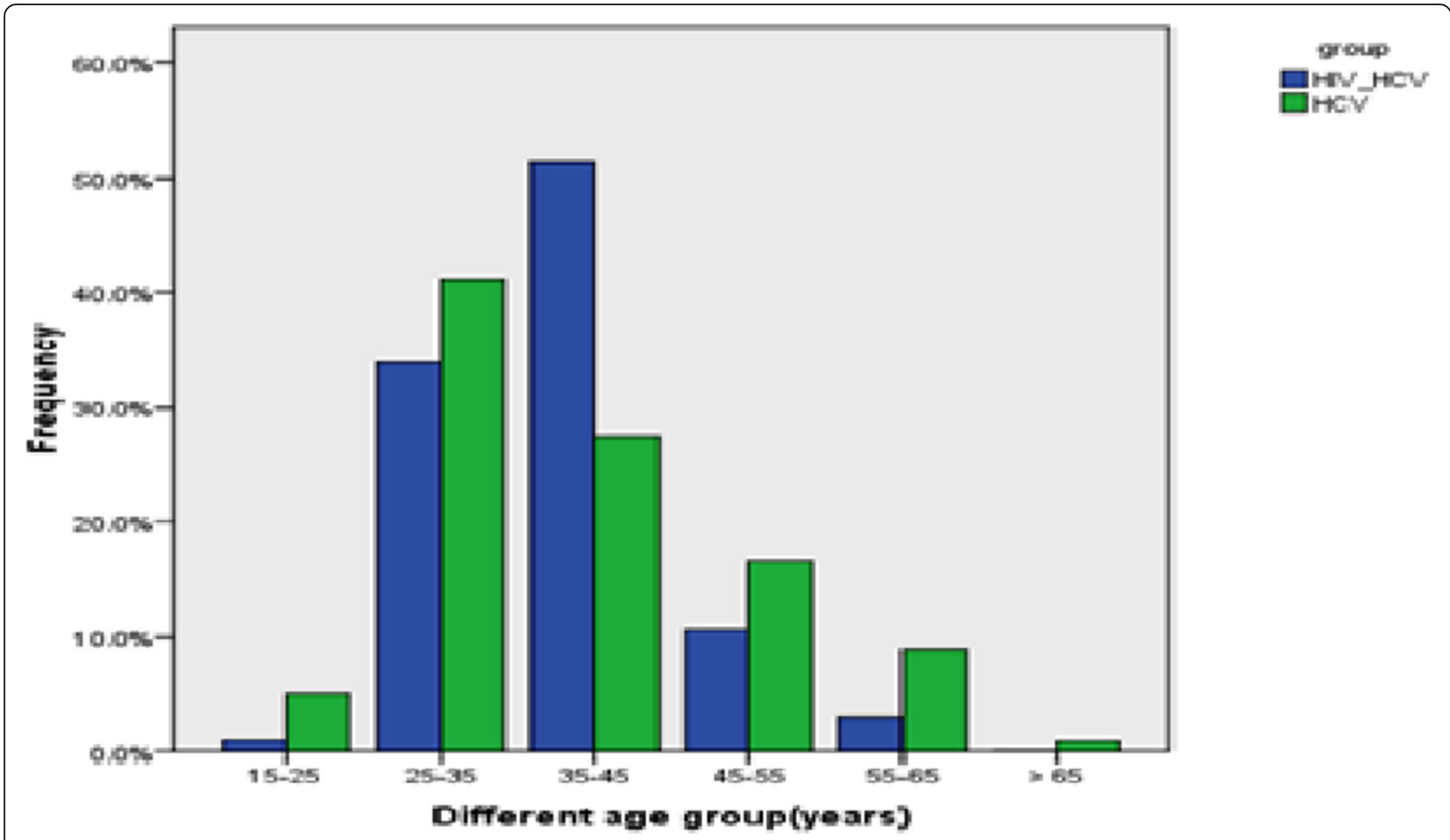

Fig. 2 Median of HCV viral loads among HCV mono- and HIV/HCV co-infected IDUs in different age groups

respectively. Multiple sex partners and alcohol drinking were two other risk factors that were evaluated only in co-infected IDUs.

Totally, as shown in Table 4, nearly $60 \%$ of HCV mono-infected and $95 \%$ of $\mathrm{HCV} / \mathrm{HIV}$ co-infected IDUs have experienced more than one risk factor.

\section{Discussion}

IDUs and hemophiliac patients are the main common HIV/HCV co-infected patients [12-15]. In this study, we determined the HIV seropositive rate among HCVinfected IDUs was $6.7 \%$, consistent with other studies performed in Iran and other countries. In other studies in Shiraz, Honarvar and Davarpanah revealed that the HIV prevalence rates among HCV infected IDUs were 6.43 and $18.3 \%$, that our result was similar to the first one $[16,17]$ as well as Rahimi-Movaghar and colleagues results which was $8.7 \%$ in Tehran [18].
However HCV SVR rate was not evaluated in the current study, but Baseline HCV loads and their GTs are the strongest factors predicting HCV SVR rate. High Mir-122 level, less favorable IL-28 (CT or TT) polymorphism and African-American race are the main host factor leading to poorer SVR [19].

It is notable that in new direct-acting antiviral (DAA) era, the importance of HCV GTs in predicting treatment response has declined significantly.

The present study results were in agreement with other previous studies that showed $\mathrm{HCV}$ viral load in $\mathrm{HIV} / \mathrm{HCV}$ co-infected IDUs was significantly higher than that among HCV mono-infected patients $[9,20,21]$. Mathews et al. showed HCV viral load in $\mathrm{HIV} / \mathrm{HCV}$ patients was approximately six times greater than that in $\mathrm{HCV}$ mono-infected patients [21]. In the present study, the difference was about ten times.

Table 2 HCV genotype pattern among Iranian HCV mono- and HCV/HIV co-infected IDUs with detectable HCV RNA

\begin{tabular}{|c|c|c|c|c|c|c|}
\hline \multirow[t]{2}{*}{ HCV infected IDUs } & \multicolumn{6}{|c|}{ HCV Genotype distribution } \\
\hline & Gt1 & Gt3 & Gt4 & Gts $1+2 / 3$ & No determined Gt & Total \\
\hline HCV mono-infected & $210(49.06 \%)$ & $128(29.9 \%)$ & $1(0.23 \%)$ & $9(2.10 \%)$ & $80(18.69 \%)$ & 428 \\
\hline HCV/HIV co-infected & $54(69.23 \%)$ & $14(17.94 \%)$ & $0(0 \%)$ & $0(0 \%)$ & $10(12.82 \%)$ & 78 \\
\hline Total & $264(52.17 \%)$ & $142(28.06 \%)$ & $1(0.19 \%)$ & $9(1.77 \%)$ & $90(17.78 \%)$ & 506 \\
\hline
\end{tabular}


Table 3 The most important risk factors and corresponding frequencies in Iranian HCV infected IDUs with or without HIV infection

\begin{tabular}{|c|c|c|c|c|}
\hline \multirow[t]{2}{*}{ HCV infected IDUs } & \multicolumn{4}{|l|}{ Risk factor } \\
\hline & Imprisonment (\%) & Tattoo (\%) & Multiple sex partners (\%) & Alcohol drinking (\%) \\
\hline HIV/HCV co-infected patients $(n=104)$ & $81(77.9 \%)$ & $29(27.8 \%)$ & $29(27.9 \%)$ & $42(40.3 \%)$ \\
\hline HCV mono-infected patients $(n=541)$ & $295(54.5 \%)$ & $161(29.31 \%)$ & - & - \\
\hline Total & $384(56.1 \%)$ & $185(27 \%)$ & - & - \\
\hline
\end{tabular}

Different studies showed HCV T-cell specific responses decreased significantly in HIV/HCV co-infected patients that were concordant with higher $\mathrm{HCV}$ chronic rate in these patients $[22,23]$.

$\mathrm{HCV}$ does not seem to have significant impacts on natural history of HIV infection, however, in post HAART era, according to different large studies; relative liver associated mortality has been increased in HIV/ $\mathrm{HCV}$ co-infected individuals due to antiretroviral therapy, as a prominent cause. However, AIDS related mortality was decreased dramatically [24].

The results of the current study revealed that HCV GT1 was the most common detected genotype in both monoand co-infected IDUs with 49 and $69 \%$ frequencies, respectively. HCV GT3 was the second most common genotype with 30 and 18\% frequencies in mono- and co- infected IDUs, respectively, consistent with our previous study [25].

This study contradicts with Berger et al. study [26] in which no correlation was seen between HIV infection and HCV viral load. The results of the current study revealed a strong correlation between $\mathrm{HCV}$ viral load and HIV co-infection as well as GT1 HCV genotype.

Since HCV viral load in HIV/HCV co-infected patients, especially those infected with HCV GT1 is higher than that among mono-infected patients infected with other HCV GTs and more rapid clinical progression in HIV/HCV co-infected patients $[11,27]$ with delayed sustained virological response (SVR) [15], an efficacious HCV treatment should be considered.

Table 4 The frequencies of risk factors in HCV mono- and HIV/ HCV co-infected IDUs

\begin{tabular}{lll}
\hline Illicit drug users $^{\text {a }}$ & $\begin{array}{l}\text { HIV/HCV co-infected } \\
\text { patients }\end{array}$ & $\begin{array}{l}\text { HCV mono-infected } \\
\text { patients }\end{array}$ \\
\hline With none other risk factor & $5(4.8 \%)$ & $191(33 \%)$ \\
IDU + 1 another risk factor & $46(44.2 \%)$ & $301(52 \%)$ \\
IDU+ 2 other risk factors & $26(25.0 \%)$ & $39(6.7 \%)$ \\
IDU+ 3 other risk factors & $8(7.7 \%)$ & Not determined \\
IDU+ 4 other risk factors & $13(12.5 \%)$ & Not determined \\
IDU+ more than 4 risk & $6(5.8 \%)$ & Not determined \\
factors & $104(100 \%)$ & $531(100 \%)$ \\
Totally &
\end{tabular}

${ }^{a}$ According to the text, risk factors comprise imprisonment, tattooing, having multiple sex partner and alcohols drinking. All of the cases in the study were drug users with or without injection history with up to 4 risk factors
In PHOTON clinical trial, researchers concluded that sofosbuvir plus ribavirin is a more effective regime than standard peg-IFN and ribavirin in the treatment of HIV/ HCV co-infected patients and SVR rate was between 84-91\%, depending on HCV GTs [28]. However, Torriani et al. has reported that SVR rate was $56 \%$ among $\mathrm{HIV} / \mathrm{HCV}$ co-infected patients 12 week after standard peg-IFN and ribavirin HCV treatment [29].

As shown in Table 3, 53 and $78 \%$ of mono- and coinfected IDUs, respectively had variable lengths of prison terms. It can be suggested that these infections with different frequencies are transmitted through the shared needles and drug-preparation equipment in jails.

As indicated in Table 4 , only $5 \%$ of $\mathrm{HIV} / \mathrm{HCV}$ coinfected IDUs were with one risk factor (illicit drug using), however, in mono-HCV IDUs this rate was $33 \%$. Ninety one percent (98/104) of HCV mono-infected experienced up to 2 risk factors while $98 \%(531 / 541)$ of $\mathrm{HCV} / \mathrm{HIV}$ of co-infected IDUs experienced up to 4 risk factors.

In the present study, we did not assess the correlation between CD4+ T-cell count and HCV viral load. As reported in previous studies, the critical point is increasing viral load in patients with impaired cellular immunity, especially HIV positive ones [30, 31]. Further investigations focusing on responses to HCV treatment among both infected groups and other factors such as viral and human genetics, are recommended.

\section{Conclusion}

Iran, one of the countries with a high rate of illicit drug use, has a large number of HCV infected IDUs that may be co-infected with HIV and/or other types of viral hepatitis. We reported a significantly high $\mathrm{HCV}$ viral load in $\mathrm{HCV} / \mathrm{HIV}$ co-infected patients, compared with $\mathrm{HCV}$ mono-infected ones. In addition, we showed that in both groups of the patients, GT1 was the dominant genotype followed by GT3. Higher GT1/GT3 ratio and HCV viral load among $\mathrm{HCV} / \mathrm{HIV}$ co-infected patients suggest more attention to the treatment of such patients.

\section{Abbreviations \\ HCV GTs: HCV genotypes; HCV: Hepatitis C Virus; IDUs: Illicit Drug Users; SVR: Sustained Virological Responses}

\section{Acknowledgments}

Our thanks go to Hassan Khajehei, PhD, for copy editing of the manuscript. We are also grateful to Ms. Sareh Roosta for statistical analysis of the data. 
The researchers gratefully appreciate SDBC staff, especially Ms. Jamei, Ms. Bagheri and Dr. Hassanabadi.

\section{Funding}

The study was supported by Grant No.91-16 and 91-17 awarded by Professor Alborzi Clinical Microbiology Research Center, Shiraz University of Medical Sciences, Shiraz, Fars, Iran.

\section{Availability of data and materials}

Not applicable.

\section{Authors' contributions}

Jamalidoust and Ziyaeyan reviewed literatures and designed the study. Jamalidoust wrote the manuscript. Ziyaeyan, Jamalidoust and Namayandeh performed the experiment. Namayandeh gathered the data. Moghadami and Ziyaeyan were responsible for administration and material patronage. All authors read and approved the final manuscript.

\section{Ethics approval and consent to participate}

Ethics approval and consent to participate was given by ethics committee of Shiraz University of Medical Sciences.

\section{Consent for publication}

Not applicable.

\section{Competing interests}

The authors declare there is no conflict of interest.

\section{Publisher's Note}

Springer Nature remains neutral with regard to jurisdictional claims in published maps and institutional affiliations.

\section{Author details}

${ }^{1}$ Department of Virology, Professor Alborzi Clinical Microbiology Research Center, Nemazi Hospital, Shiraz University of Medical Sciences, P. O. Box: 31 Shiraz 71937-11351, Iran. ${ }^{2}$ Department of Virology, Professor Alborzi Clinical Microbiology Research Center, Nemazi hospital, Shiraz University of Medical Sciences, Shiraz 71937-11351, Iran.

Received: 15 September 2016 Accepted: 5 July 2017

Published online: 11 July 2017

\section{References}

1. Easterbrook, P.J., et al., Diagnosis of viral hepatitis. Curr Opin HIV AIDS, 2017.

2. Alter MJ. Epidemiology of viral hepatitis and HIV co-infection. J Hepatol. 2006;44(1 Suppl):S6-9.

3. Garbuglia AR, et al. HCV core antigen and HCV-RNA in HIV/HCV co-infected patients with different HCV genotypes. BMC Infect Dis. 2014;14:222.

4. Sherman $\mathrm{KE}$, et al. Hepatitis $\mathrm{C}$ virus prevalence among patients infected with human immunodeficiency virus: a cross-sectional analysis of the US adult AIDS Clinical Trials Group. Clin Infect Dis. 2002;34(6):831-7.

5. Smith DJ, et al. Hepatitis C virus (HCV) disease progression in people who inject drugs (PWID): a systematic review and meta-analysis. Int J Drug Policy. 2015:26(10):911-21.

6. Malekinejad $M$, et al. High hepatitis $C$ virus prevalence among drug users in Iran: systematic review and meta-analysis of epidemiological evidence (2001-2012). Int J Infect Dis. 2015;40:116-30.

7. Lichterfeld $M$, et al. Clinical outcomes of HIV-HCV co-infection in a large cohort of hemophiliac patients. J Inf Secur. 2005;50(3):221-8.

8. Page $\mathrm{EE}$, et al. Clearance of hepatitis $\mathrm{C}$ virus RNA from serum in HIV/ hepatitis $C$ virus coinfection indicates eradication from peripheral blood mononuclear cells. AIDS. 2010;24(9):1267-71.

9. The Nerve Growth Factor: thirty-five years later. EMBO J, 1987. 6(9): p. 2856.

10. Di Martino $\mathrm{V}$, et al. The influence of human immunodeficiency virus coinfection on chronic hepatitis $C$ in injection drug users: a long-term retrospective cohort study. Hepatology. 2001;34(6):1193-9.

11. Sulkowski MS, Benhamou Y. Therapeutic issues in HIV/HCV-coinfected patients. J Viral Hepat. 2007;14(6):371-86.

12. Troisi $\mathrm{CL}$, et al. A multicenter study of viral hepatitis in a United States hemophilic population. Blood. 1993;81(2):412-8.
13. Kimanga DO, et al. Prevalence and incidence of HIV infection, trends, and risk factors among persons aged 15-64 years in Kenya: results from a nationally representative study. J Acquir Immune Defic Syndr. 2014;66(Suppl 1):S13-26.

14. Greub $\mathrm{G}$, et al. Clinical progression, survival, and immune recovery during antiretroviral therapy in patients with HIV-1 and hepatitis C virus coinfection: the Swiss HIV cohort study. Lancet. 2000;356(9244):1800-5.

15. Beisel C, et al. German cohort of HCV mono-infected and HCV/HIV coinfected patients reveals relative under-treatment of co-infected patients. AIDS Res Ther. 2014;11:16.

16. Honarvar B, et al. Blood-borne hepatitis in opiate users in iran: a poor outlook and urgent need to change nationwide screening policy. PLoS One. 2013:8(12):e82230.

17. Jahanbakhsh Sefidi F, et al. Distribution of hepatitis $C$ virus genotypes in Iranian chronic infected patients. Hepat Mon. 2013;13(1):e7991.

18. Rahimi-Movaghar A, et al. HIV, hepatitis C virus, and hepatitis B virus coinfections among injecting drug users in Tehran. Iran Int J Infect Dis. 2010; 14(1):e28-33.

19. Abe $\mathrm{H}$, et al. New proposal for response-guided peg-interferon-plus-ribavirin combination therapy for chronic hepatitis $C$ virus genotype 2 infection. J Med Virol. 2013;85(9):1523-33.

20. Bonacini M, Lin HJ, Hollinger FB. Effect of coexisting HIV-1 infection on the diagnosis and evaluation of hepatitis C virus. J Acquir Immune Defic Syndr. 2001:26(4):340-4.

21. Matthews-Greer JM, et al. Comparison of hepatitis $C$ viral loads in patients with or without human immunodeficiency virus. Clin Diagn Lab Immunol. 2001;8(4):690-4.

22. Danta M, et al. Impact of HIV on host-virus interactions during early hepatitis C virus infection. J Infect Dis. 2008;197(11):1558-66.

23. Morishima $\mathrm{C}$, et al. Preservation of intrahepatic hepatitis $\mathrm{C}$ virus (HCV)specific CD4+ $T$ cell responses despite global loss of CD4+ T cells in HCV/ HIV coinfection. J Infect Dis. 2007;196(4):577-86.

24. Rotman $Y$, Liang TJ. Coinfection with hepatitis $C$ virus and human immunodeficiency virus: virological, immunological, and clinical outcomes. J Virol. 2009:83(15):7366-74.

25. Jamalidoust $M$, et al. Determining hepatitis $C$ virus genotype distribution among high-risk groups in Iran using real-time PCR. World J Gastroenterol. 2014;20(19):5897-902

26. Berger A, et al. Hepatitis C plasma viral load is associated with HCV genotype but not with HIV coinfection. J Med Virol. 1996;48(4):339-43.

27. Piroth $L$, et al. Does hepatitis $C$ virus co-infection accelerate clinical and immunological evolution of HIV-infected patients? AIDS. 1998;12(4):381-8.

28. Corchado S, et al. Liver fibrosis, host genetic and hepatitis $C$ virus related parameters as predictive factors of response to therapy against hepatitis $C$ virus in HIV/HCV coinfected patients. PLoS One. 2014;9(7):e101760.

29. Torriani FJ, et al. Peginterferon Alfa-2a plus ribavirin for chronic hepatitis C virus infection in HIV-infected patients. N Engl J Med. 2004;351(5):438-50.

30. Hisada $M$, et al. Increased hepatitis $C$ virus load among injection drug users infected with human immunodeficiency virus and human $T$ lymphotropic virus type II. J Infect Dis. 2003;188(6):891-7.

31. Neukam K, et al. Prediction of response to pegylated interferon plus ribavirin in HIV/hepatitis C virus (HCV)-coinfected patients using HCV genotype, IL28B variations, and HCV-RNA load. J Hepatol. 2012;56(4):788-94.

\section{Submit your next manuscript to BioMed Central and we will help you at every step:}

- We accept pre-submission inquiries

- Our selector tool helps you to find the most relevant journal

- We provide round the clock customer support

- Convenient online submission

- Thorough peer review

- Inclusion in PubMed and all major indexing services

- Maximum visibility for your research

Submit your manuscript at www.biomedcentral.com/submit 